Militery Technical College Kobry Elkobbah, Cairo, Egypt

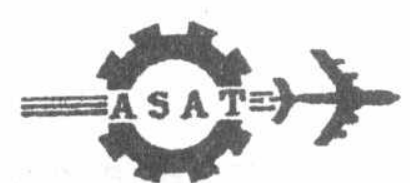

$8^{\text {th }}$ International Conference on Aerospace Sciences \& Aviation Technology

\title{
STUDIES ON RELIABILITY OF POLYESTER RESINS IN PLASTICIZING POLY(VINYL CHLORIDE).
}

\author{
Abdel-Azim A. Abdel-Azim ${ }^{*}$ and A. Elbaz Elsaild ${ }^{+}$
}

\section{ABSTRACT}

Modern technology introduced reinforced plastics in various applications in aerospace fields. The plastic materials in these fields certainly need different additives to improve their physical and mechanical properties. A series of polyesters resins having different structures and molecular weights have been prepared. The molecular weights of the prepared polyesters were determined via end group analysis. These polyesters were blended with dioctyl phthalate (DOP) and the efficiencies of these blends as plasticizers for PVC were evaluated. It was proved that some of the prepared aliphatic polyesters improve the action of the traditional low molecular weight plasticizer. This conclusion was attained by monitoring the mechanical properties (tensile - \% of elongation - hardness) throughout a whole year.

Keywords : Polyester, Resin, Plasticizer, Plasticization, Poly(vinyl chloride), PVC, Polyesterification, Ethylene glycol, Diethylene glycol, Triethylene glycol, Butylene glycol, Phthalic anhydride, Adipic acid, Sebacic acid, Succinic acid, Compatibility.

* To whom all correspondence should be addressed

* Professor, Egyptian Petroleum Research institute, Nasr City, Cairo,Egypt.

+ Military Technical College, Kobry El-Kobba, Cairo, Egypt 


\section{INTRODUCTION}

A Plasticizer has long been defined as a material incorporated into a plastic material to increase its workability and its flexibility. In this broad sense, plasticizers of many kinds were in common use even in prehistoric times. A plasticizer may be incorporated into a resin like PVC in order to impart a new property to the original polymer. In this respect phosphates and chlorinated hydrocarbons are flame retarding plasticizers. Aliphatic dicarboxylic acid esters, adipates, sebacates, and azelates impart good flexibility at low temperatures. Another example is the use of butyl benzyl phthalate (BBP), the industry standard for strain resistance, for vinyl floor covering [1] as low temperature flexibility. There is no known plasticizer that can fulfill all the plasticizer requirements. Liquid plasticizers with good general properties and low viscosity are likely show bad aging properties owing to volatility on storage for long periods. This is one of the reasons why the plastics industry is interested in polymeric plasticizers. It is necessary that the molecular weight of polymeric plasticizers must range within definite limits, that is between 1000 and 30000, but molecular weights from 1000 to about 8000 afford the best performance [1]. According to Jones [2], the efficienciy of a plasticizing material decreases with increasing molecular weight. Therefore, it is often necessary to combine high molecular weight plasticizers with low molecular weight ones to combine their characteristics.

There are very many potential starting materials available for the preparation of polyesters [3-7]. One or more varieties of glycols or acids can be used in this respect. The choice of raw materials is governed by many rules concerned with the relation between compatibility of the prepared polyester with the resin to be plasticized when these polyesters are used as plasticizers.

The present investigation aims to prepare a series of polyesters by fusion method via polycondensation reaction at elevated temperatures between glycols and dibasic acids or anhydrides and study their efficiency as plasticizers for PVC. 


\section{EXPERIMENTAL}

Materials: polyhydric alcohols, ethylene glycol (EG), diethylene glycol (DG), triethylene glycol (TG) and 1,3 butylene glycol (BG) and dibasic acids, succinic acid (SU), adipic acid (AD) and sebacic acid (SE) as well as phthalic anhydride (PHA) were reagent grade and used without further purification. All Chemicals were obtained from Aldrich.

Preparation of polyesters: The polyester resins were prepared by reacting the appropriate amounts of saturated dibasic acid or acid anhydride and glycols according to the ratios tabulated in Table 1. The average number of ether linkage of the glycol systems and the total carbon atoms in the repeating units are tabulated in the last two columns in Table 1 . Once the various glycols and acids or anhydrides were weighed and charged into a kettle, they were constantly agitated and heated until a desired acid value has been reached. In the initial phase of the reaction, the drop in the acid value was rapid and the increase in the viscosity was quite slow. Towards the late stages of the reaction, the reverse was true. Twenty two polyester resins were prepared by the method described in ref. [3]. The polyester resins were analyzed for acid and hydroxyl values [8], for the sake of calculating the molecular weights via end group analysis.

Preparation of Plasticized PVC Sheets: Ba-Zn stabilizer for PVC, known as IRGASTAB BZ 556, obtained from CIBA-GIEGY was used for heat stabilizing the PVC during the preparation of the test sheets. The utilized quantity of Ba$\mathrm{Zn}$ stabilizer was $2.5 \mathrm{wt.}$-\% with respect to the weight of the PVC resin. The selection of this concentration was based on the early investigations [9-11].

In the present investigation the Dry blending method was applied for the polyesters having moderate viscosity. In this method, the appropriate amount of plasticizer is totally absorbed into the desired grade of PVC resin by stirring for a few minutes at $50^{\circ} \mathrm{C}-80^{\circ} \mathrm{C}$ to yield a dry powder barely distinguishable in outward appearance from the original resin [12].

Here the plasticizer blends (viscous polyester + dioctyl phthalate, DOP) and heat stabilizer were mixed with PVC powder directly by stirring without a need of being firstly dissolved in a solvent. The temperature of the blend was raised to $60^{\circ} \mathrm{C}$ while stirring for $30 \mathrm{~min}$. 
On the other hand, the solid polyesters were incorporated into the sheets using the technique described by Taverdet and Vergnaud [13]. In this respect, the solid polyester was blended with DOP and the heat stabilizer. The mixture was dissolved in the least quantity of acetone solvent and added to the PVC powder to yield paste. The paste was then stirred vigorously and allowed to stand for several hours before molding to evaporate the solvent.

The quantities of the PVC resin and the plasticizers utilized for preparing the test sheets were: 80 wt.- $\%(40 \mathrm{~g})$ PVC powder (K 61), 10 wt.. $\%(5 \mathrm{~g})$ Polyester and $10 \mathrm{wt} . \%$ (5 g) DOP.

After incorporation of the plasticizer and the heat stabilizer to the PVC powder, the plasticized PVC sheets were prepared by the aid of a hot melt press. A stainless steel frame having the dimensions of $20 \times 20 \times 0.1 \mathrm{~cm}$ was used for preparing the sheets utilized in the tensile measurements while another frame having a thickness of $0.4 \mathrm{~cm}$ was used for shaping the sheets utilized for measuring the hardness.

It has been proposed $[14,15]$ that at low temperature $\left(165^{\circ} \mathrm{C}-170^{\circ} \mathrm{C}\right)$ the time required for completing the pressing process is about $12 \mathrm{~min}$. Using such a long time in the pressing process at the above mentioned temperature range leads to a reduction in the efficiency of the added stabilizer. Accordingly, a total pressing time of $5 \mathrm{~min}$ at temperature $180^{\circ} \mathrm{C}$ and pressure ranging between 8-10 tons was used during the present investigation.

According to the selected conditions, different plasticized test sheets were prepared by applying an initial pressing stage for $2 \mathrm{~min}$. at the above specified pressure. The pressure was then released for few seconds to get rid off the air bubbles. The molten mixture was exposed to the same pressure again for another $3 \mathrm{~min}$. The pressed molten sample was then cooled under the same pressure in order to obtain non deformed flat sheet of uniform thickness.

Tensile Properties of PVC Sheets: Measurements of tensile strength of the prepared sheets in the form of standard dumbbell-shaped test specimens under defined conditions of temperature, humidity and testing machine speed, stress-strain diagrams were measured using a Zwick mechanical testing 
machine. A great care was exercised to ensure that all samples are prepared in exactly the same way and slippage while testing was prevented insofar as possible. Each sample was measured at least five times and the reported value, for each specimen, was taken as the average of these five measurements.

Hardness: In the present study the hardness (Shore D) was measured using a Zwick hardness tester (3102) according to ASTM D 2240-75. The thickness of the specimens was $4 \mathrm{~mm}$. For better reproducibility, a constant load was used to press the indentor against the specimens. The hardness value was taken as an average of ten readings from different locations.

\section{RESULTS AND DISCUSSION}

Present investigation deals with the study of the plasticization potency of different polyester / DOP blends. In this respect, the prepared polyesters were blended with DOP in an equivalent proportions (50:50 wt.- \%). To emphasis the effectiveness of these blends as plasticizers, it is desired to compare the mechanical properties of the PVC sheets plasticized by these blends with that plasticized with DOP alone. It is of interest to mention that the prepared polyesters were designed with great care in such a way to be compatible with PVC.

The measured acid and hydroxyl values of the synthesized twenty two polyester resins are listed in Table (2), These values were used for calculating the molecular weights via end group analysis. The obtained $\left\langle M_{n}\right\rangle$ values as well as the physical states of the investigated polyesters and the prediction of their compatibility with PVC are also listed in Table (2).

Compatibility of polyesters with PVC: There is remarkably little published information concerning the relationship between the dependence of compatibility of polyester plasticizer with PVC on the structure of these polyesters. In general, the compatibility depends on both melting point and degree of polar character of polyester. In this respect, introduction of an oxygen atom into the straight chain diols, as in diethylene and triethylene glycols, causes a pronounced drop in the melting points of the derived polyesters. This is attributed to an increase in the flexibility of the chain, which presumably leads to an increase in the magnitude of the entropy, thus 
reducing the melting point. On other hand, the introduction of oxygen atoms into the polyester chain leads to an increase in the polarity of the polyester. Both parameters cause an increase in the compatibility of the polyester with PVC [16]. On the other hand, incorporating benzene or cyclohexane ring in the polyester chain through 1,4-positions raises the melting temperature of the produced polyesters as compared with the acyclic analogies [16].

An important objective, therefore, was to prepare liquid polyesters and some polyesters containing benzene rings which form a part of the chain through 1,2-positions to find out their compatibility with PVC.

The compatibility predictions of the prepared polyesters with PVC are listed in Table (2). These predictions are based on the structural parameters (Table 1) of the studied polyesters. Unfortunately, Table (2) shows that the all polyesters including phthalic anhydride are solid polyesters except P12 at which TG and BG are used as glycol system. Incorporation of these higher glycols results in an increase of the number of ether linkage in the repeating units and hence yields liquid polyester at ambient temperature (i.e. polyester with low melting point). The incompatibility predictions of the polyesters P7 . P11 with PVC, as shown in Table (2), are based on their high melting points (solid polyesters at ambient temperature). While the incompatibility of $\mathrm{P} 12$ is predicted as a result of the low value of the average number of carbon atorns (7) in the repeating units.

The overall polarity of a polyester plasticizer is an important factor governing its compatibility with PVC. As the number of carbon atoms in the dicl and dicarboxylic acid components is reduced the polarity of the resulting polyester increases, and vice versa. The polarity is also increased by introducing etheroxygen atoms into the chain of one or more of the reactants. The required balance between the total number of carbon atoms and the number of ester groups apparently exists when the number of carbon atoms is not less than 10 , and not greater than about 20 [16]; but these limits are not known with certainty. No really systematic investigation of these relationships appears to have been published.

Based on the above mentioned relationships, one may arrive to the speculation that P5 is incompatible while $\mathrm{P} 6$ and $\mathrm{P} 19$ possess limited compatibility. The compatibility predictions will be confirmed in the following 
section by testing the mechanical properties (tensile and hardness shore D) of the plasticized PVC sheets.

Tensile properties: In the present work, not only the initial part of the stressstrain curves were used to obtain generalized data on the properties of the plasticized PVC sheets but also its ultimate stress and the relative elongation at rupture. The obtained values, for PVC sheets plasticized with polyesters under investigation blended with DOP (50 : 50 wt.- \%), are listed in Table (3). These values represent the data measured after seven days and after one year.

It is well known [1] that the hardness and tensile modulus of a PVC compound increase measurably during the period immediately following processing. A recent study carried out by Guerrero [17] has shown that even when the moduli of the thermally dried casted PVC sheets, are measured just 15 min after casting process, there was an evident anti-plasticization effect. Accordingly, in the present investigation, the plastisized PVC test samples were stored at room temperature for seven days before these tests were measured.

In the group of plasticizers P1-P4, the average number of carbon atoms of the repeating units lies between 10 and 20. Accordingly, the controlling parameters are the number of ether linkage and the molecular weight of the polyester. The average number of ether linkage of P1, P2, P3 and P4 are 0.0, $1.0,2.0$ and 0.0 , respectively. Table (3) shows that the highest elongation and lowest tensile strength are assigned for P3 in both measurements i.e., after one week and one year. This reveals that P3 is the most compatible within this group. Upon comparing the elongation data, after one year, of plasticized PVC with P1/DOP-P4/DOP blends and DOP as sole plasticizer, it is observed that the percentage of reduction in elongation in the latter case is $34.2 \%$ while the highest percentage of reduction when DOP was blended with the polyesters P1-P4 is $25.6 \%$.

With respect to $\mathrm{P} 5$, the tensile strength and percentage of elongation after one week, as shown in Table (3), are $10.8 \mathrm{~kg} \mathrm{~cm}^{-2}$ and 161, respectively. The former value slightly increased to $11.2 \mathrm{~kg} \mathrm{~cm}^{-2}$ and the latter one slightly decreased to 140 after one year. These petty changes in conjunction with the original low value of elongation and high value of tensile strength indicate that 
P5 is a moderately compatible plasticizer and not incompatible as predicted theoretically.

Apart from P7-P11 and P19, all other polyesters are liquids possessing different degrees of plasticization efficiency. Within the group of polyesters P13 - P15, the highest polarity is assigned for P14 (see Table (1), average number of ether linkage is 1). The incorporation of $T G$ in $P 14$ instead of DG and $B G$ in $\mathrm{P} 13$ and $\mathrm{P} 15$, respectively, increases also the total number of carbon atoms of the reactants. As a result of these two parameters it was presumed a good compatibility of this polyester. The tensile strength and the elongation data after one week reveal that P14 acts as good plasticizer. The data of the tensile test after one year indicate that the highest compatibility within this group is assigned for P15. This may be attributed to the high value of molecular weight (3252) and low acid value (7.2) compared with molecular weights of 2429 and 2671 for P13 and P14, respectively and acid values of 18 and 16.7, respectively. Certainly, there is a lack of systematic investigations on the influence of the acid value on the plasticization efficiency. The present. finding may offer a great body of evidence on the effect of the acid value of the plasticizer on PVC properties. However, the present finding runs in harmony with the assumption [18] that the increase in the acid value of the plasticizer reduces its stability.

Table (3) shows that PVC sheets plasticized with polyesters P7 - P11 afford poor mechanical properties after one week. The data of tensile strength and $\%$ of elongation reveal that the polyesters P7 - P11 are not compatible with PVC. This finding agrees with the theoretical prediction of compatibility as shown in Table (2). Accordingly, these sheets were not considered for evaluation after one year.

Hardness: In the present work, the hardness shore D is used to categorize the efficiency and compatibility of the prepared polyesters as plasticizers for PVC. The obtained values, for PVC sheets plasticized with polyesters under investigation blended with DOP (50:50 wt.- \%), are listed in Table (4). These values represent the data measured after ten days and followed throughout the year.

The hardness data, in general, indicate that the lower the value of hardness the better the plasticization efficiency of the plasticizer. On the other harid, the 
little increase in the hardness value with time is associated with a better compatibility due to the polymer - polymer miscibility [19-21] which reflects on the extent of exudation of the polyester plasticizer.

With respect to the plasticization efficiency, the data of the hardness [Table (4)] reveal that the most potent samples are P3, P4, P15, P16, P20 and P21. These polyesters afford initial values $\leq 63$. Table (1) shows that the average number of carbon atoms / reactants used for preparing these polyesters is bigger than 9. The influence of the number of ether linkage on the plasticization efficiency is obviously noticed in case of P2, P14, P17 and P18. These polyesters provide initial values of hardness ranging between 65 and 66. These low values of hardness reflect the efficiency of these polyesters in plasticizing PVC. This efficiency may be attributed to the effect of combination of a total number of carbon atoms exceeding 10 and an appropriate degree of polarity afforded by the ether linkage incorporated in the chains of these polyesters (see Table $1 \& 4$ ).

Apart from the group of polyesters based on phthalic anhydride (P7-P12) other polyesters (P1, P5, P19 and P22) furnish moderate plasticization efficiencies (hardness $=70: 72$ ).

An attempt to elucidate the compatibility of the polyesters under investigation with PVC was performed by comparing the values of hardness after one year with the initial values. Careful inspection of the data tabulated in Table (4) reveals that the lowest increase in hardness i.e., the lowest exudation of the plasticizer is for P18. However, the data lead to the speculation that P2, P14, $\mathrm{P} 17$ and $\mathrm{P} 18$ are the best polyester plasticizers among the prepared samples. This speculation is based on the initial and final hardness values from which the extent of exudation can be estimated. Based on the percentage of the increase of hardness, the extent of exudation can be arranged according to the sequence $\mathrm{P} 14>\mathrm{P} 2>\mathrm{P} 17>\mathrm{P} 18$. Accordingly, it can be said that $\mathrm{P} 18$ is the best plasticizer among the studied ones. This finding runs in harmony with the data obtained by measuring the tensile properties after one year. The initial values hardness and the corresponding values after one year for the PVC sheets plasticized with P18-DOP blend and DOP reveal that the increase in hardness is about $14 \%$ for the former plasticizer system while it is about $23 \%$ for the latter one. 


\section{CONCLUSION}

The data reveal that the incorporation of polyester plasticizers may improve the plasticization potency of DOP by extending its workability time due to the reduction of the volatility of the plasticizer mixture.

\section{REFERENCES}

[1] W.V. Titow, "PVC Technology", 4th Ed., Elsevier Applied Scince Publishers Ltd. (1984).

[2] J.Jones, Trans. Inst. Rubber Ind., 21, 298 (1946).

[3] A. A. Abdel-Azim, Polym. Bull., 35, 229 (1995).

[4] A.A. Abdel-Azim, H.M. Bahram, M.S. Farahat, Polym. Advanc. Technol., 5, 269 (1994).

[5] A.A. Abdel-Azim, I.A. Attia and E.S. Nasr Polym.-Plast. Technol. Eng., 34(1), 79 (1995).

[6] A. A. Abdel-Azim, E.S. Nasr and Farahat M.S., Polymer J. 26(4), 423 (1994).

[7] I.A. Attia, M.S. Abdel-Halim and A. A. Abdel-Azim, Polym. Bull., 34, 377 (1995).

[8] W.R. Sorenson, T.W. Campbell "Preparative Method of Polymer Chemistry", Interscience, New York (1968).

[9] K. Volka, E. Czako and Z. Vymazal, Eur. Polym. J., 16, 149 (1980).

[10] Z. Vymazal, E. Czako, K. Volka, J. Stepek, R. Lukas, M. Kolinsky and K. Bouchal, Eur. Polym. J., 16, 151 (1980).

[11] Z. Vymazal, K. Volka, E. Czako, and J. Stepek, Eur. Polym. J., 17, 77 (1981).

[12] L.T. Carleton and E. Mishuk, J. Appl. Polym. Sci., 8, 1221 (1964).

[13] J.L. Taverdet and J.M. Vergnaud, J. Appl. Polym. Sci., 31, 111 (1986).

[14] E. Czako, Z. Vymazal, K. Volka, I. Stibor and J. Stepek, Eur. Polym. J., 15, 81 (1979).

[15] G. Scott,M. Tahan and J. Vyvoda, Eur. Polym. J., 14, 377 (1978).

[16] B.Parkyn, F. Lamb and B.V. Clifton, "Polyesters", vol 2, lliffe, London (1967).

[17] S.J Guerrero, Macromolecules, 22, 3480 (1989). 
[18] T.S. Gancheva, P.D. Dinev and K.G. Bukovska, J. Appl. Polym. Sci., 28, 1551 (1983).

[19] A. A. Abdel-Azim, Y. B. Wagdy and E. M. Abdel-Bary, Polymer, 39(12), 2543 (1998).

[20] A. A. Abdel-Azim, M.S. Farahat, A.M. Atta and Y. B. Wagdy, J. Appl. Polym. Sci., 69, 1471 (1998).

[21] P. Munk, Hattam P., Du Qiannguo and A. A. Abdel-Azim, J. Appl. Polym. Sci., Appl. Polym. Symp., 45, 289 (1990). 
Table 1 Constituents and structural parameters (<-O-> and TCN) of the prepered polyesters

\begin{tabular}{|c|c|c|c|c|c|c|c|c|c|c|}
\hline \multirow[t]{2}{*}{ code } & \multicolumn{4}{|c|}{ Glycol (mole) } & \multicolumn{4}{|c|}{$\begin{array}{l}\text { Dicarboxylic acid } \\
\text { (mole) }\end{array}$} & \multirow[t]{2}{*}{$<-\mathrm{O}-\rangle^{*}$} & \multirow[t]{2}{*}{$\mathrm{TCON}^{+}$} \\
\hline & EG & DG & TG & $B G$ & SU & $A D$ & SE & PHA & & \\
\hline P1 & 1.10 & - & - & - & - & 0.50 & 0.50 & - & 0.0 & 10 \\
\hline P2 & - & 1.10 & - & - & - & 0.50 & 0.50 & - & 1.0 & 12 \\
\hline P3 & - & - & 1.10 & - & - & 0.50 & 0.50 & - & 2.0 & 14 \\
\hline $\mathrm{P4}$ & - & - & - & 1.10 & - & 0.50 & 0.50 & - & 0.0 & 12 \\
\hline P5 & 1.10 & - & - & - & 0.50 & 0.50 & -- & - & 0.0 & 7 \\
\hline P6 & 1.10 & - & - & - & 0.50 & - & 0.50 & - & 0.0 & 9 \\
\hline P7 & 0.55 & 0.55 & - & - & -- & - & - & 1.00 & 0.5 & 5 \\
\hline P8 & 0.55 & - & 0.55 & - & - & - & - & 1.00 & 1.0 & 6 \\
\hline P9 & 0.55 & - & - & 0.55 & - & - & -- & 1.00 & 0.0 & 5 \\
\hline P10 & - & 0.55 & 0.55 & -- & - & - & -- & 1.00 & 1.5 & 7 \\
\hline P11 & - & 0.55 & -- & 0.55 & - & - & - & 1.00 & 0.5 & 6 \\
\hline $\mathrm{P} 12$ & - & -- & 0.55 & 0.55 & - & - & - & 1.00 & 1.0 & 7 \\
\hline P13 & 0.55 & 0.55 & - & - & - & 1.00 & - & - & 0.5 & 9 \\
\hline P14 & 0.55 & - & 0.55 & - & - & 1.00 & - & - & 1.0 & 10 \\
\hline P15 & 0.55 & -- & -- & 0.55 & - & 1.00 & - & - & 0.0 & 9 \\
\hline P16 & - & 0.55 & 0.55 & -- & - & 1.00 & -- & - & 1.5 & 11 \\
\hline P17 & - & 0.55 & - & 0.55 & - & 1.00 & - & - & 0.5 & 10 \\
\hline P18 & - & - & 0.55 & 0.55 & - & 1.00 & - & - & 1.0 & 11 \\
\hline P19 & 1.10 & - & - & - & - & - & 0.50 & 0.50 & 0.0 & 8 \\
\hline P20 & - & \begin{tabular}{|l|}
1.10 \\
\end{tabular} & - & - & - & - & 0.50 & 0.50 & 1.0 & 10 \\
\hline P21 & - & -- & 1.10 & -- & - & - & 0.50 & 0.50 & 2.0 & 12 \\
\hline P22 & - & - & - & 1.10 & - & - & 0.50 & 0.50 & 0.0 & 10 \\
\hline
\end{tabular}

" Average number of ether linkage in the glycol system

+ Total number of carbon atoms in the reactants 
Table 2 Acid values, hydroxyl numbers, molecular weights,physical states of the prepared polyesters and theoretical prediction of their compatibility with PVC.

\begin{tabular}{|l|c|c|c|c|c|}
\hline code & $\begin{array}{c}\text { Acid } \\
\text { value }\end{array}$ & $\begin{array}{c}\text { Hydroxyl } \\
\text { number }\end{array}$ & $\begin{array}{c}\left\langle\mathbf{M}_{\mathbf{n}}\right\rangle \\
\times \mathbf{1 0}^{-3}\end{array}$ & $\begin{array}{c}\text { State } \\
\text { at } \mathbf{2 5}^{\circ} \mathrm{C}\end{array}$ & $\begin{array}{c}\text { predicted } \\
\text { compatibility }\end{array}$ \\
\hline P1 & 18.4 & 27.2 & 2.461 & waxy & compatible \\
\hline P2 & 20.4 & 23.2 & 2.573 & liquid & compatible \\
\hline P3 & 11.5 & 20.8 & 3.474 & liquid & compatible \\
\hline P4 & 27.4 & 29.8 & 1.962 & liquid & compatible \\
\hline P5 & 12.3 & 37.6 & 2.249 & liquid & incompatible \\
\hline P6 & 13.4 & 29.1 & 2.640 & waxy & limited compatibility \\
\hline P7 & 17.9 & 26.1 & 2.550 & solid & incompatible \\
\hline P8 & 23.0 & 25.7 & 2.304 & solid & incompatible \\
\hline P9 & 24.9 & 28.4 & 2.105 & solid & incompatible \\
\hline P10 & 28.3 & 39.0 & 1.667 & solid & incompatible \\
\hline P11 & 19.7 & 26.3 & 2.439 & solid & incompatible \\
\hline P12 & 28.7 & 29.7 & 1.921 & liquid & incompatible \\
\hline P13 & 18.0 & 28.2 & 2.429 & liquid & compatible \\
\hline P14 & 16.7 & 25.3 & 2.671 & liquid & compatible \\
\hline P15 & 7.2 & 27.3 & 3.252 & liquid & compatible \\
\hline P16 & 16.4 & 23.6 & 2.805 & liquid & compatible \\
\hline P17 & 16.0 & 25.7 & 2.691 & liquid & compatible \\
\hline P18 & 20.4 & 27.2 & 2.357 & liquid & compatible \\
\hline P19 & 12.8 & 25.4 & 2.937 & solid & limited compatibility \\
\hline P20 & 22.3 & 24.1 & 2.418 & liquid & compatible \\
\hline P21 & 21.3 & 20.5 & 2.684 & liquid & compatible \\
\hline P22 & 9.3 & 23.9 & 3.380 & liquid & compatible \\
\hline
\end{tabular}


Table 3 Tensile strength (TS) and \% elongation (E) of plasticized PVC sheets with various polyesters / DOP blends.

\begin{tabular}{|l|c|c|c|c|}
\hline \multirow{2}{*}{ code } & \multicolumn{2}{|c|}{ After one week } & \multicolumn{2}{c|}{ After one year } \\
\cline { 2 - 5 } & TS (kgcm $\left.{ }^{-2}\right)$ & E \% & TS (kgcm $\left.{ }^{-2}\right)$ & E \% \\
\hline P1 / DOP & 9.0 & 209 & 10.3 & 160 \\
\hline P2 / DOP & 8.7 & 221 & 10.6 & 165 \\
\hline P3 / DOP & 7.6 & 242 & 9.7 & 180 \\
\hline P4 / DOP & 8.9 & 225 & 9.8 & 177 \\
\hline P5 / DOP & 10.8 & 161 & 11.2 & 140 \\
\hline P6 / DOP & 9.3 & 184 & 10.6 & 168 \\
\hline P7 / DOP & 16.4 & 18 & -- & - \\
\hline P8 / DOP & 12.7 & 105 & -- & - \\
\hline P9 / DOP & --- & --- & - \\
\hline P10 / DOP & 12.0 & 120 & -- & - \\
\hline P11 / DOP & 13.1 & 90 & -- & - \\
\hline P12 / DOP & 12.4 & 110 & -- & 120 \\
\hline P13 / DOP & 9.9 & 175 & 11.4 & 178 \\
\hline P14 / DOP & 8.4 & 232 & 9.8 & 192 \\
\hline P15 / DOP & 8.4 & 230 & 9.1 & 180 \\
\hline P16 / DOP & 7.8 & 236 & 9.3 & 186 \\
\hline P17 / DOP & 8.2 & 215 & 9.0 & 195 \\
\hline P18 / DOP & 8.0 & 220 & 8.8 & - \\
\hline P19 / DOP & 11.0 & 144 & -- & 150 \\
\hline P20 / DOP & 8.8 & 190 & 9.4 & 150 \\
\hline P21 / DOP & 8.4 & 198 & 9.6 & 130 \\
\hline P22 / DOP & 9.3 & 158 & 10.5 & 182 \\
\hline DOP & 7.9 & 244 & 8.9 & - \\
\hline
\end{tabular}


Table 4 Hardness (shore D) for PVC sheets containing different polyesters blended with DOP (50/50 wt \%) as a function of time.

\begin{tabular}{|l|c|c|c|c|c|c|}
\hline \multirow{2}{*}{ code } & \multicolumn{6}{|c|}{ Hardness (shore D) after different times in days } \\
\cline { 2 - 7 } & $\mathbf{1 0}$ & $\mathbf{8 0}$ & $\mathbf{1 5 0}$ & $\mathbf{2 1 5}$ & $\mathbf{2 5 0}$ & $\mathbf{3 8 7}$ \\
\hline P1 / DOP & 70 & 70 & 74 & 76 & 76 & 76 \\
\hline P2 / DOP & 65 & 67 & 67 & 75 & 75 & 75 \\
\hline P3 / DOP & 61 & 62 & 67 & 70 & 73 & 75 \\
\hline P4 / DOP & 60 & 67 & 67 & 71 & 74 & 76 \\
\hline P5 / DOP & 72 & 74 & 75 & 77 & 77 & 78 \\
\hline P6 / DOP & 65 & 69 & 70 & 70 & 76 & 77 \\
\hline P7 I DOP & 80 & 81 & 81 & 82 & 84 & 84 \\
\hline P8 / DOP & 78 & 78 & 80 & 82 & 82 & 83 \\
\hline P9 / DOP & 79 & 79 & 81 & 83 & 84 & 85 \\
\hline P10 / DOP & 71 & 78 & 79 & 81 & 82 & 82 \\
\hline P11 / DOP & 76 & 77 & 79 & 83 & 83 & 84 \\
\hline P12 / DOP & 75 & 75 & 75 & 80 & 82 & 84 \\
\hline P13 / DOP & 71 & 71 & 73 & 78 & 79 & 81 \\
\hline P14 / DOP & 65 & 68 & 71 & 74 & 76 & 76 \\
\hline P15 / DOP & 62 & 68 & 71 & 75 & 76 & 76 \\
\hline P16 / DOP & 60 & 62 & 65 & 68 & 76 & 76 \\
\hline P17 I DOP & 66 & 68 & 69 & 75 & 76 & 76 \\
\hline P18 / DOP & 65 & 66 & 67 & 70 & 70 & 74 \\
\hline P19 / DOP & 70 & 72 & 72 & 79 & 81 & 82 \\
\hline P20 / DOP & 63 & 65 & 69 & 76 & 76 & 77 \\
\hline P21 / DOP & 63 & 70 & 70 & 75 & 76 & 78 \\
\hline P22 I DOP & 72 & 75 & 76 & 82 & 82 & 83 \\
\hline DOP & 57 & 57 & 59 & 60 & 67 & 70 \\
\hline
\end{tabular}

